MISCELLANEOUS PAPER NO. 4-713

\title{
TRAFFICABILITY OF SNOW IN ARCTIC AND SUBARCTIC REGIONS \\ by
}

B. G. Schreiner

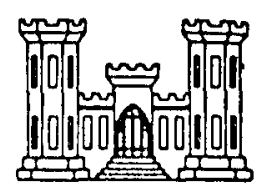

March 1965

Sponsored by

U. S. Army Materiel Command

Conducted by

U. S. Army Engineer Waterways Experiment Station CORPS OF ENGINEERS

Vicksburg, Mississippi

ARMY-MRC VICKSBURG, MISS. 
This paper discusses one phase of the rork condusted at the U. S. Ariny Ingineer Waterways Experiment Station (WES) under the sponsorship and guidance of the Directorate of Research and Development, U. S. Army Matexiel Command, as part of Task 1-V-0-21701-A-046-02, "Surface Mobility."

The study discussed was accomplished by the Trafficability section of the Army lobility Rescarch Branch, Mobility and Environmental Division, VES, under the supervision of licssrs. W. J. Turnbull, W. G. Shocliley, S. J. Knight, and E. S. Rush. This paper was prepared and presented by Iir. B. G. Schreiner, Trafficability Section, at U. S./Canadian joint meeting of the International Socicty for Terrain-Vehicle Systems in Houghton, Michigan, held on 9-10 February 1965. 


\section{Introduction}

Trafficability is the characteristic of a terrain that indicates its ability to support the passage of a ground vehicle. The principal aim of the trafficability studies being conducted by the Waterways Experiment Station is to develop suitable correlations between simple terrain measurements and vehicle performance.

One of the terrain surface conditions that poses trafficability problems in northern areas is snow. Several agencies have responded to these problems and have performed trafficability studies on various snow conditions. The U. S. Army Cold Regions Research and Engineering Laboratory conducted some snow trafficability tests many years ago in the mountains of Colorado, and later in Michigan and Greenland. The U. S. Army Land Locomotion Laboratory and Transportation Research Command have studied snow problems in Michigan and elsewhere; and the Canadian Deferce Research Board has made several studies in Canada.

\section{Snow Trafficability Studies of the Waterways Experiment Station}

The Waterways Experiment station for a long time concentrated most of its efforts on the trafficability of mineral soils; however, in recent

* Engineer, Trafficability Section, Army Mobility Research Branch, Mobility and Environmental Division, U. S. Army Engineer Waterways Experiment Station, CE, Vicksburg, Miss. 
years it has also turned its attention to snow. The work in snow has now progressed sufficiently to warrant discussion. This paper will describe briefly the most important correlations derived through trafficability testing in snow.

The Waterways Experiment Station began snow trafficability studies in 1954. Since then it has conducted test programs on the Greenland Ice Cap and in the mountains of Colorado, and has participated in programs conducted by other agencies at Houghton, Michigan, and Ft. Churchill and Kapuskasing, Canada. Detailed results of the work in snow, including many facets not covered in this paper, have been published in WES Technical Memorandum No. 3-414, Trafficability of Snow, Reports 1-4. Snow conditions tested

According to SIPRE's "Simplified Field Classification of Natural Snow Types for Engineering Purposes," the snow conditions tested in Greenland included dry, moist, and wet fine-grained snow, and wet coarsegrained snow; the condition tested in the United States and Canada has been primarily dry snow. The surface snow on the ice cap ranged in hardness from soft to very hard for the dry snow, and soft to very soft for the moist and wet snow. The dry continental snow tested ranged from soft to very soft throughout the entire snowpack. Instruments and technjques used

The principal instrument used to measure snow trafficability has been the cone penetrometer together with a compaction test apparatus modified from the standard remolding test apparatus used in fine-grained soils. Prior to selection of these instruments, however, some 12 other instruments and the snow property measurements obtained with them were 
evaluated during pilot phases of the study. Results showed that the standard trafficability instruments appeared to be the most useful of those studied.

Vehicles tested

Whether a terrain is trafficable or not depends not only on the specific features of the terrain, but also on the characteristics of the vehicle. To achieve a better understanding of the trafficability problems in snow, a variety of vehicle systems was tested, including self-propelled, tracked and wheeled vehicles, and 10-ton sleds. The ground-contact pressures of the tracked vehicles ranged from 1.0 psi for the Theker Sno-Cat to $10.5 \mathrm{psi}$ for the M48 tank. The gross weights of the tracked vehicles ranged from 5,000 $\mathrm{Ib}$ for the $\mathrm{M} 29 \mathrm{C}$ weasel to $96,000 \mathrm{Ib}$ for the $\mathrm{M} 48$ tank. Because of their poor performance, only a few tests have been run with conventional wheeled vehicles. The tests with sleds were made to compare the performance of steel runners and two types of plastic runners. Vehicle tests conducted

Vehicle tests were of three general types: single self-propelled, towing, and towed. A single self-propelled test is one in which a selfpropelled vehicle travels forward and backward in a straight-line path in the same tracks until it becomes immobilized or until it completes 40-50 passes. A towing test is used to determine the drawbar pull a selfpropelled vehicle can develop under prescribed conditions, whereas a towed test is made to determine the amount of pull required to tow a vehicle. In the tests discussed in this paper, the towed vehicle was a sled equipped, with one of the sled-runner materials mentioned earlier. The original purpose of the tests was to test areas where snow conditions were strong 
enough to support traffic of a given vehicle and other areas where the snow was weak enough to cause a vehicle to become immobilized, and thus delineate "go" and "no-go" performance on the basis of snow properties. Few snow conditions tested were found to be'poor enough to cause immobilization of conventional tracked vehicles in a few straight-line passes, or good enough to support traffic of conventional wheeled vehicles.

The action of tracked vehicles in snow is such that if the initial strength of the snow is less than that required to support the vehicle, the vehicle will compact the snow until the strength of the snow equals or exceeds that required. This condition occurred without critical vehicle sinkage. Since snow conditions were not encountered that permitted correlation on the basis of go-no go for 50 passes, most vehicle performance measurements were in terms of drawbar pull and results of towed-vehicle tests.

Test results

Because of differences in snow conditions and the effects of snow depth on the tests in Colorado, this discussion is divided into ice-cap snow tests and continental-mountain snow tests.

Ice-cap snow tests. In ice-cap snow, tracked vehicles occasionally became immobilized on natural, steep slopes (if steep enough, a slope can cause the immobilization of any vehicle on any medium) and on steep slopes created by the formation of ridges and swales in repetitive-pass testing. Heavy, high-ground-pressure vehicles, such as the M48 tank with a ground pressure of.10.5 psi, occasionally had difficulty in maneuvering in some Greenland snow conditions. However, in no case were any of the tracked vehicles tested in Greenland immobilized in a few passes while traveling 
on level snow and not towing a load.

In multiple-pass traffic in the same ruts, ridges and swales begin to develop along the rut surface after approximately 10 passes; if traffic is continued, these ridges and swales may cause the vehicle to become immobilized. The amplitude and frequency of the ridges and swales apparently depend upon such vehicle characteristics as gross weight, ground pressure, track length, etc. After-traffic snow strength, in terms of cone index, shows an orderly change with number of passes applied, initial strength of the snow, and load applied. The magnitude of the change is dependent upon such factors as vehicle contact pressure and gross weight, the number of passes applied by the vehicle, and the grain size and wetness of the snow. All wet snow, molst snow, and the softer dry snow increase in strength with compaction, as shown in fig. la, but hard to very hard, dry snow loses strength when compacted because the bond between the snow grains is destroyed.

Vehicle performance on the basis of depth of rut formed while the vehicle is traveling over virgin snow can be correlated directly with snow property measurements. It has been found that the correlations are improved by separating the snow types on the basis of wetness, as shown in fig. Ib.

Generally speaking, in the snow trafficability tests the rut created on the first pass was about two-thirds as deep as it became after 10 passes. Fig. 2 is a plot comparing the depth of rut after the first pass (Y-axis) with that after the loth pass (X-axis).

During the first pass of a vehicle, the snow compacted by a track of the vehicle is deformed downward with little lateral movement, as 
shown by the resultant stress patterns beneath the rut surface. The depth of the deformation or "stress bulb" is dependent upon the gross weight of the vehicle and the initial strength of the snow. As soon as the strength of the snow equals the force of the load applied, no significant further deformation occurs; hence, no further development of the stress bulb takes place. It was found that for the same contact pressure, the depth of the stress bulb was shallow in dry, medium-hard snow and deep in soft, wet snow $(f i g \cdot 3)$

For the towing tests, in which performance was measured in terms of maximum drawbar pull that the vehicles could develop under certain snow conditions, the best performance with all vehicles tested was obtained on moist snow, followed by that on wet snow which appeared to have a slight advantage over dry snow for most vehicles (fig. 4). For all snow types, the girderized track systems of the engineer tractors generally gave best performance, followed by the weasel which has a comparatively high number of bogies for the contact area of the track. Little performance difference appeared between the high-speed tractor and the $M 48$ tank. This indicates that the more uniformly the track system loads the snow, the better the vehicle performs. It was found also that ground-contact pressure affected the towing performance of a vehicle. Tests run on a dry snow with a cone index of 20 indicate that for a vehicle to tow 40 percent of its gross weight in this type of snow, the ground-contact pressure should not exceed 4 psi (fig. 5).

Results of the sled tests (fig. 6) indicate that the kinetic friction of Teflon-coated runners over dry snow is approximately one-half that of steel, while that of Kel-F plastic-coated runners falls about halfway 
between the Teflon and steel values. Tests of static friction show highest coefficients for wet snow and lowest for dry snow. As the snow becomes moist, the differences in friction coefficients become less and the values themselves become smaller. For wet snow, friction coefficients are a little higher than for moist snow. Unit loads between 2.5 and 5.0 psi had no appreciably different effects on kinetic friction.

Continental-mountain snow tests. More consideration was given to depth of snowpack in studies of continental snow, since it is relatively shallow (usually less than $4 \mathrm{ft}$ deep) compared to deep ice-cap snow. The depth of the mountain snow tested ranged from 12 to $45 \mathrm{in}$. The snow condition was always soft to very soft (strengths in terms of cone index ranged from 2 to 12) with wetness classifications of moist or dry.

The multiple-pass traffic test results show that sinkage (rut depth) can be correlated with snow depth for a particular vehicle (fig. 7). The first pass of a vehicle is the most difficult. The only tracked vehicle tested that became immobilized was an M5A4 tractor, and immobilization occurred in about $45 \mathrm{in.} \mathrm{of} \mathrm{snow.} \mathrm{Difficulties} \mathrm{were} \mathrm{encountered} \mathrm{in} \mathrm{steer-}$ ing tracked vehicles in snow when the depth exceeded about $30 \mathrm{in.}$. Tracked vehicles with high ground pressures performed better in snow 30 in. or less in depth than lower ground-pressure vehicles, because the former vehicles sank through the soft snow and developed traction near the ground surface.

The trafficability of soft, dry snow was improved by compaction and age-hardening .

Wheeled vehicles operating without traction devices became immobilized in snow depths in excess of about 25 percent of their wheel diameter. 
Results of the towing tests indicate that vehicle performance in terms of maximum drawbar pull can be correlated with snow depth; as snow depth increases, drawbar pull decreases. For one vehicle, the Ma9C weasel (fig. 8), it was found that in soft, dry snow, snow depths greater than 30 in. did not affect the drawbar pulls because at this depth the entire stress bulb was contained within the snow. First-pass drawbar pull was greater in moist than in dry snow. The total tractive coefficient (maximum arawbar pull plus rolling resistance) was about the same for all tracked vehicles tested ( $f i g \cdot 9$ ).

\section{Summary of Test Findings}

On the basis of results of field test programs of admittedly limited extent, snow type, wetness, depth, and strength appear to be of significance. Generally, all tracked vehicles can travel over the level, permanently covered, deep-snow areas of the Greenland Ice Cap and over the subarctic snow when it is less than about $36 \mathrm{in}$. deep. Maximum drawbar pulls on ice-cap snow were found to vary in a narrow range, from about 35 to 45 percent of the gross weight of the vehicles; while on subarctic snow, the maximum drawbar pull depended significantly upon the snow depth. 


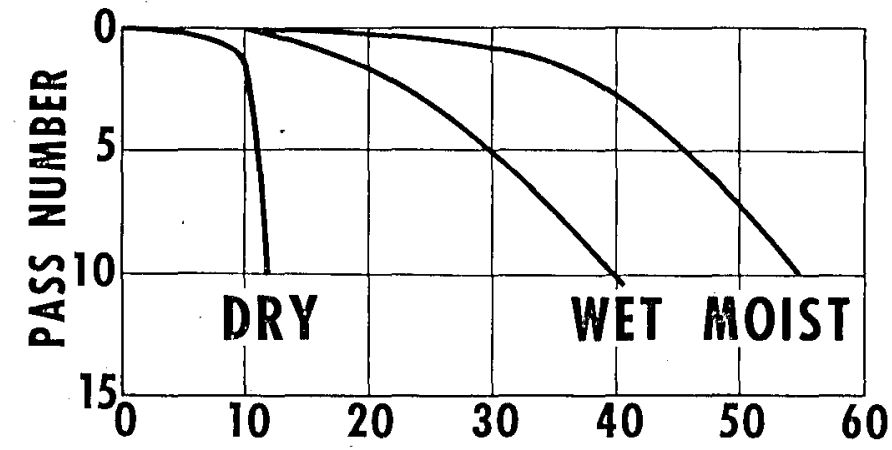

AVG CONE INDEX 0- TO 6-IN. LAYER

FIG. Ia. EFFECT OF REPETITIVE

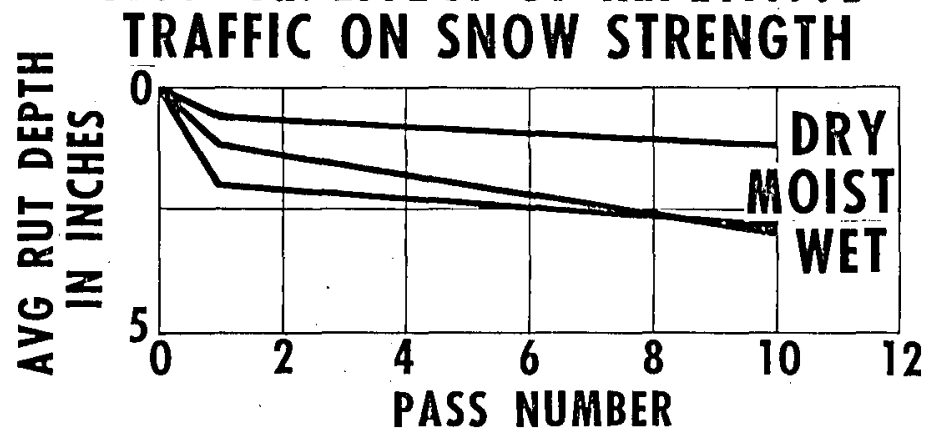

FIG. Ib. EFFECT OF REPETITIVE

TRAFFIC ON RUT DEPTH

EXAMPLE OF EFFECTS OF

TRAFFIC ON ICE CAP SNOW,

WEASEL (5400 LB)

FIG. 1 

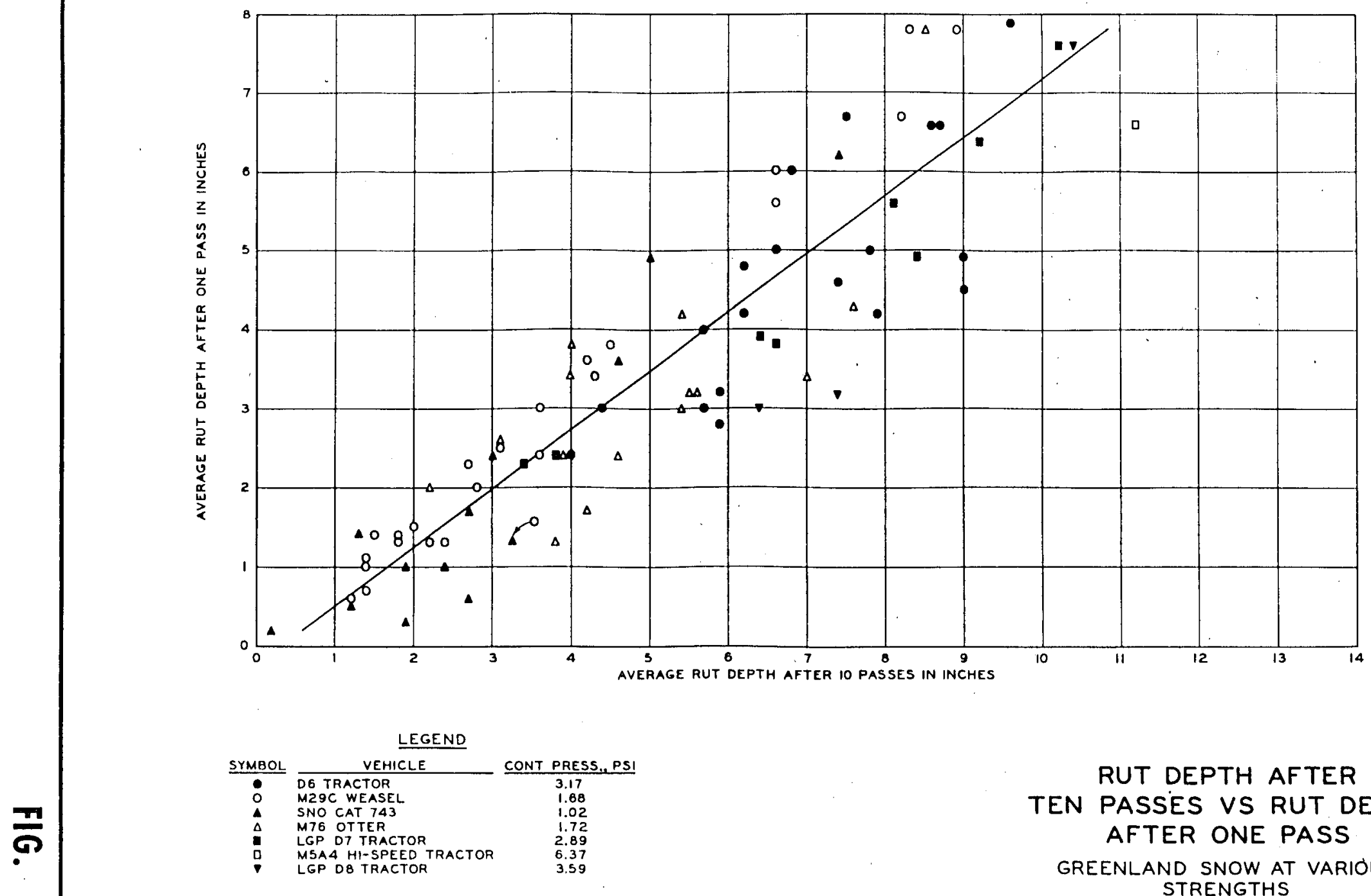

RUT DEPTH AFTER TEN PASSES VS RUT DEPTH AFTER ONE PASS

GREENLAND SNOW AT VARIOUS STRENGTHS 


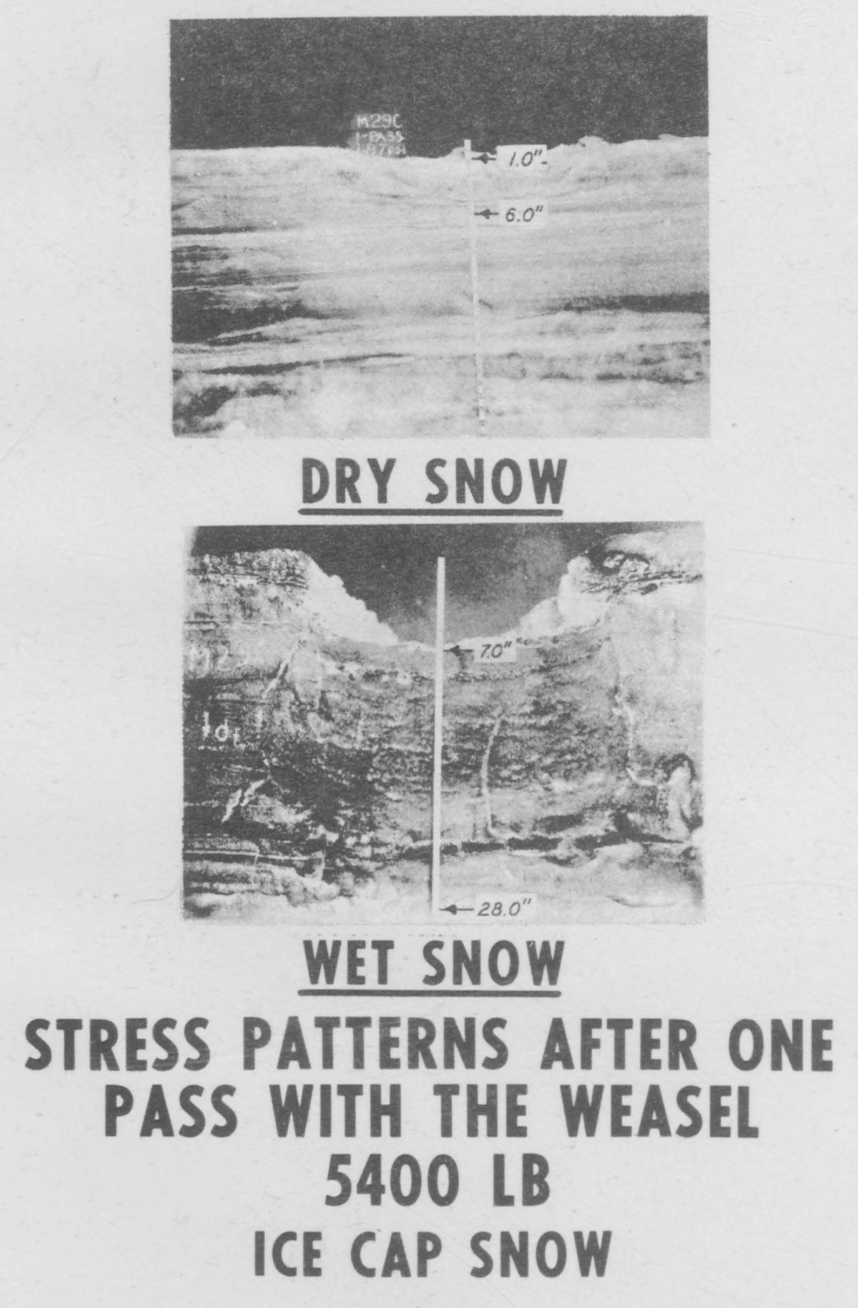

FIG. 3. 


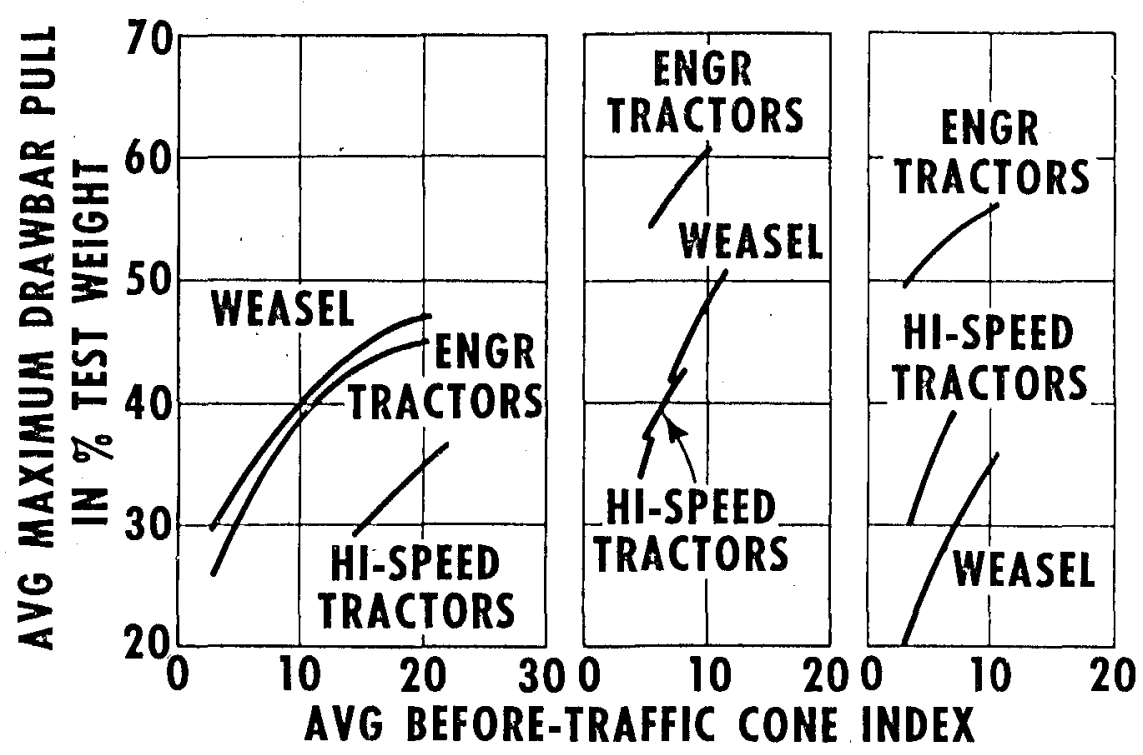

DRY SNOW MOIST WET SNOW

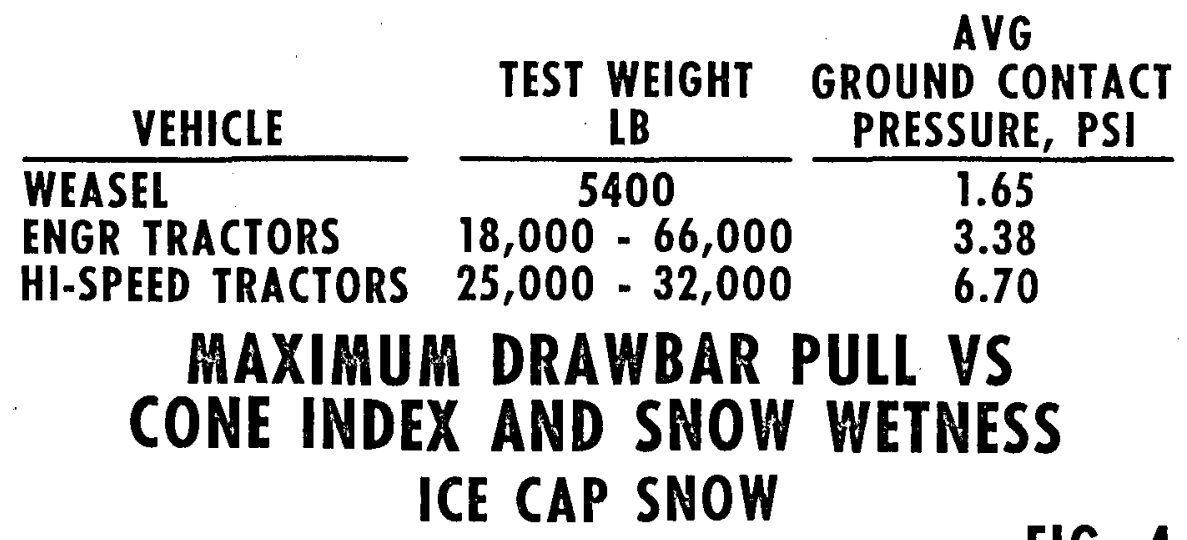

FIG. 4 


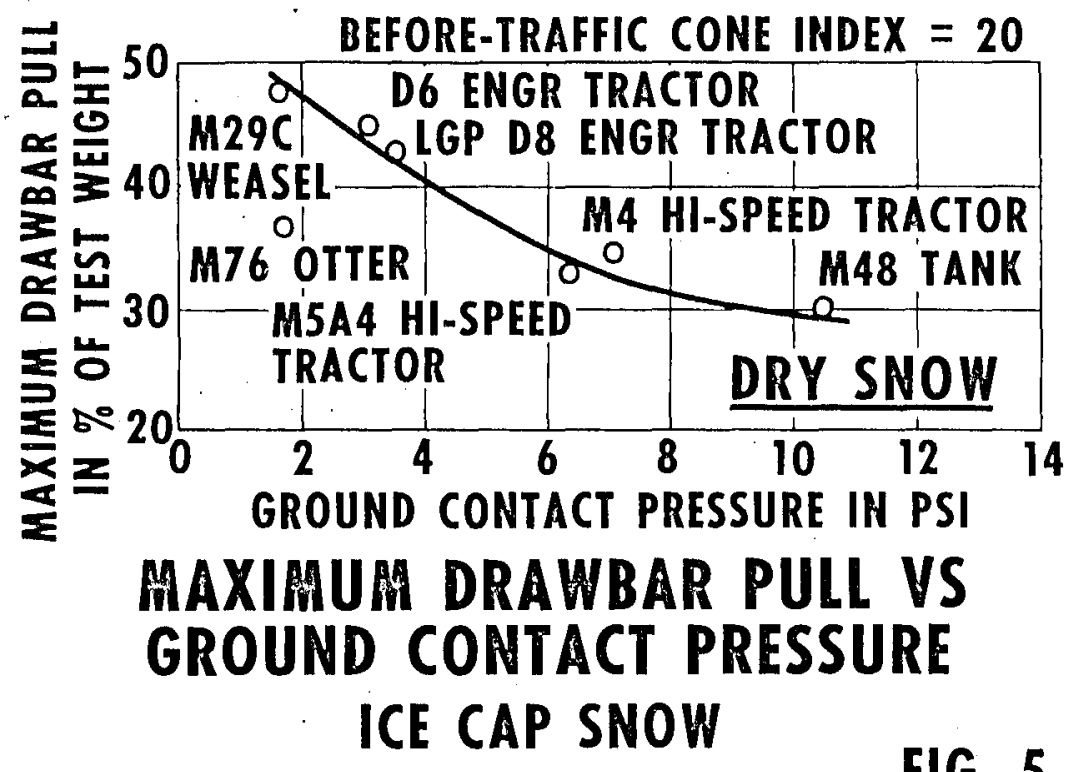

FIG. 5 


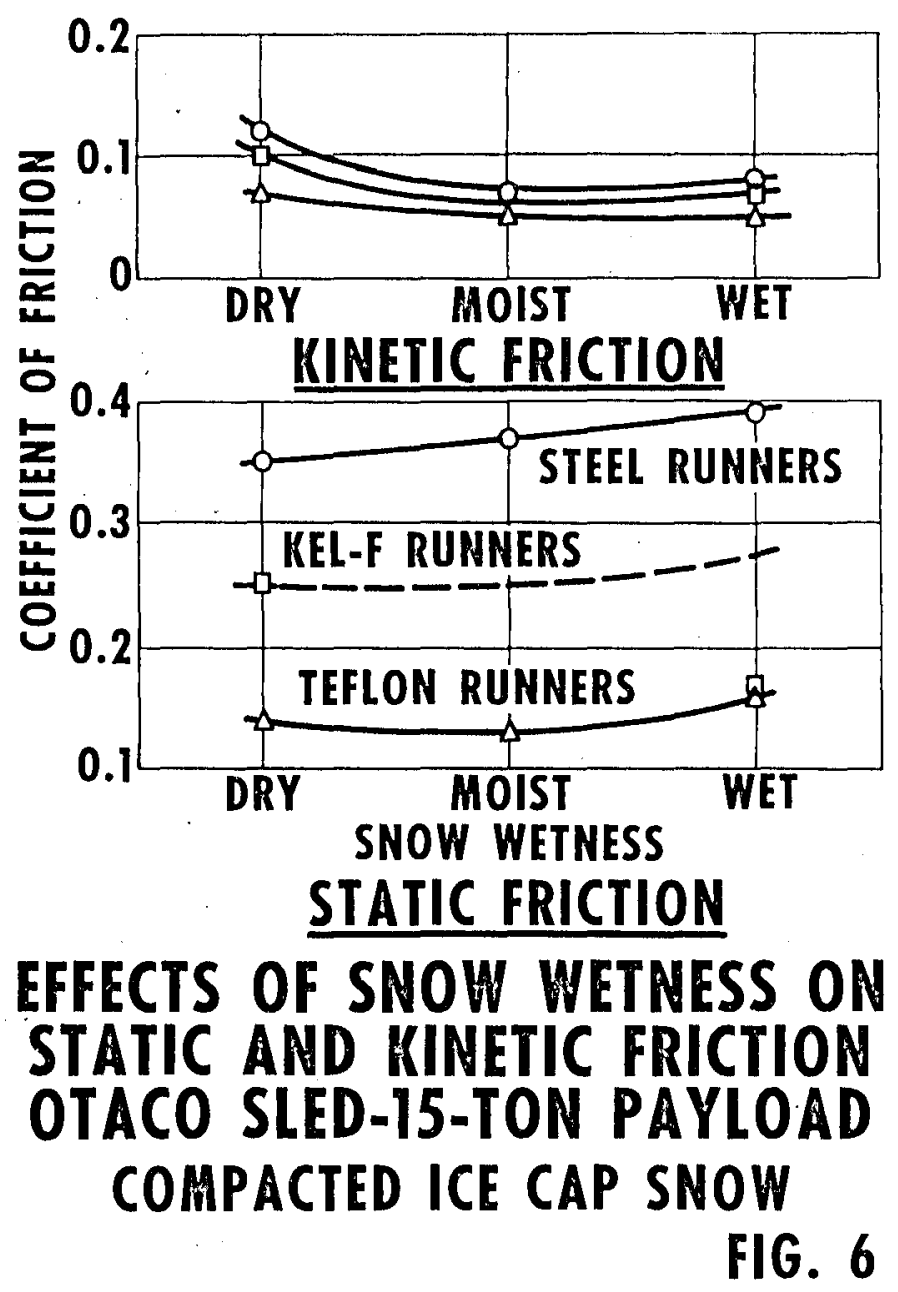




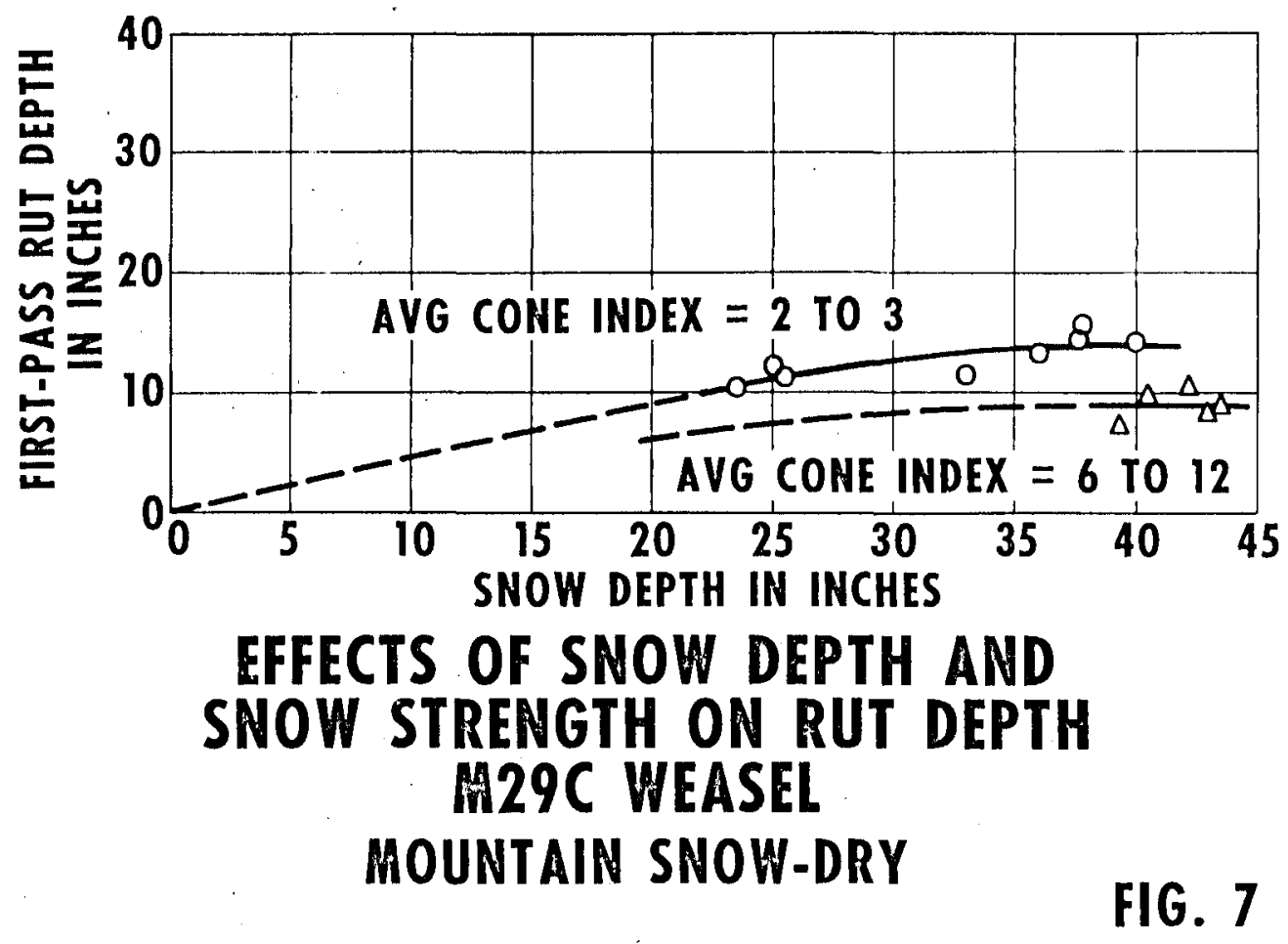




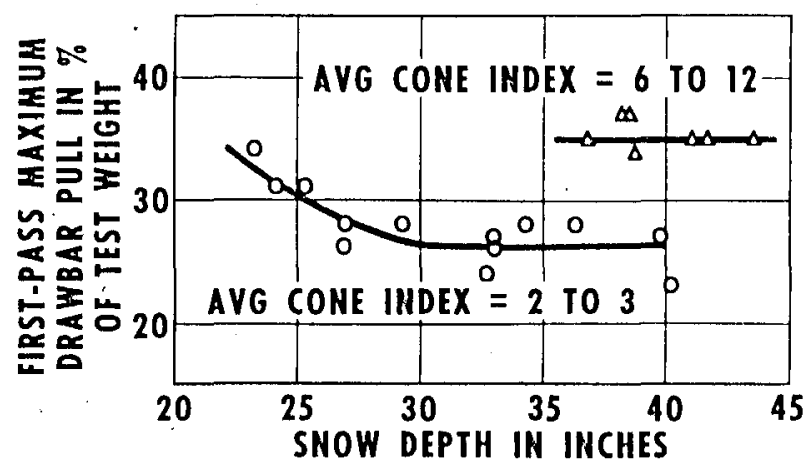

EFFECTS OF SNOW DEPTH

AND SNOW STRENGTH ON

MAXIMUM DRAWBAR PULL

H29C WEASEL

MOUNTAIN SNOW-DRY

FIG. 8. 

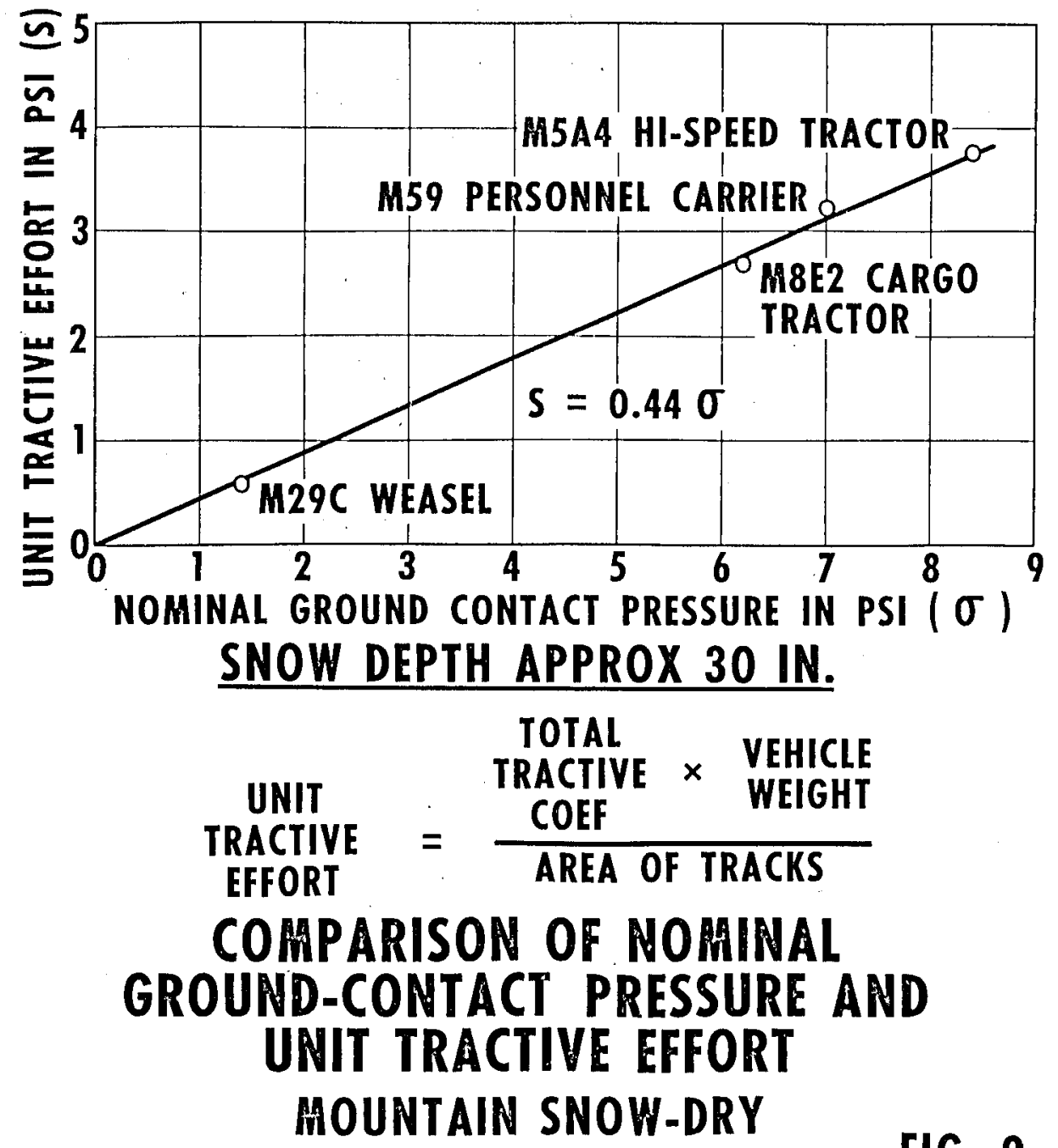

FIG. 9 
